\title{
Deriving Site Index Equation and Curves for Plantation Forest
}

\section{Lee, Sang-Hyun}

Department of Forest Resources, College of Agriculture, Sunchon National University I Department of Forestry, Chonnam National University | Faculty of Forestry, College of Agriculture, Chonbuk National University

\section{Imada, Morio}

Laboratory of Forest Planning, Division of Forest Management, Dep. of Forests and Forest Product Sciences, Faculty of Agriculture, Kyushu University | Department of Forest Resources, College of Agriculture, Sunchon National University I Department of Forestry, Chonnam National University

\section{Kim, Kae-Hwan}

Department of Forest Resources, College of Agriculture, Sunchon National University I Department of Forestry, Chonnam National University | Faculty of Forestry, College of Agriculture, Chonbuk National University

\section{Seo, Byung-Soo}

Department of Forest Resources, College of Agriculture, Sunchon National University I Department of Forestry, Chonnam National University | Faculty of Forestry, College of Agriculture, Chonbuk National University

他

https://doi.org/10.5109/24388

出版情報: 九州大学大学院農学研究院紀要. 45 (2)，pp. 395-403，2001-02-28. Kyushu University バージョン：

権利関係 : 
J. Fac. Agr., Kyushu Univ., 45 (2), 395-403 (2001)

\title{
Deriving Site Index Equation and Curves for Plantation Forest
}

\author{
Sang-Hyun Lee*, Morio Imada, Kae-Hwan Kim*, Byung-Soo Seo*, \\ Chang-Heon Lee*, Chong-Min Park*, Hag-Mo Kang** \\ and $\mathrm{Ki}-$ Wan An***
}

\author{
Laboratory of Forest Planning, Division of Forest Management, Dep. of Forests \\ and Forest Product Sciences, Faculty of Agriculture, Kyushu University, \\ Fukuoka 812-8581, Japan \\ (Received October 26, 2000 and accepted November 10, 2000)
}

\begin{abstract}
Douglas-fir (pseudotsuga menziesii Mirb. Franco) ranks as the second most important plantation tree species after radiata pine in New Zealand. Site index equations to derive site index curves for Douglas-fir plantations have been developed based on mid-term repeated measurement data sets, and then site index curve (base age 40 years) was developed. The function was developed by algebraic difference equation method. Of the projection functions tested, Gompertz polymorphic equation showed the higher precision of the fitting. Ninety-five percent of the observations used to fit model could be predicted within $\pm 1.7 \mathrm{~m}$ of the actual values. Polymorphic family of site index curves, hence, which reflect different shapes for the different site index classes, were derived from the Gompertz equation. This function represents measurement times $T_{1}$ and $T_{2}$ as $T_{2}-T_{1}$, while the Hossfeld and Schumacher functions, which had the second third lower MSE values, encapsulate $T_{1}$ and $T_{2}$ as $T_{2} / T_{1}$. The applicability of the Gompertz function, therefore, was enhanced with this study data set that contain medium measurement cycles.
\end{abstract}

\section{INTRODUCTION}

Developing reliable height prediction based on unbiased and accurate height models, and site index curves is an essential task in forest yield estimation. This is because height growth, particularly that of dominant and co-dominant trees, is generally the most stable stand growth statistic that is directly measured.

The most frequently used representation of site productivity is site index defined as the average total height of the dominant or co-dominant trees in even-aged stands at a specified index age. Typically, the base index age is set at 25, 50 and 100 years. The base index age is specified somewhat less than rotation age (Goelz and Burk, 1992).

Theoretically height growth is sensitive to differences in site quality, slightly affected by varying density levels and species composition, relatively stable under varying thinning intensities, and strongly correlated with volume. For many important plantation species, height growth is rarely affected by variation in stand density (Assmann, 1970; Lanner, 1985). Consequently, site quality estimation procedures based on stand height

\footnotetext{
* Faculty of Forestry, College of Agriculture, Chonbuk National University, Chonju, 561-756, Korea.

** Department of Forest Resources, College of Agriculture, Sunchon National University, Sunchon, 540-742, Korea.

*** Department of Forestry, Chonnam National University, Kwangju, 500-757, Korea
} 
information are the most commonly used techniques for evaluating site productivity.

Site index curves can be classified into three types: 1) anamorphic curves; 2) polymorphic-disjoint curves; and 3) polymorphic-nondisjoint curves according to the nature of the height/age curve families they generate (Clutter et al., 1983; Borders et al., 1984). Anamorphic curves have the shape parameter $(\beta)$ eliminated, constraining the resultant curves to have similar shape, but with different asymptote parameters $(\alpha)$. Thus, for any two curves in an anamorphic family, the height of one curve at any age is a constant proportion of the height of the other curve at the same age. Polymorphic equations have the shape parameter $(\beta)$ which allows each curve the freedom to change in shape, while asymptote parameters $(\alpha)$ may, or may not vary over the curves in the family (Rennolls, 1995). Hence, there is no constant proportionality like in anamorphic curves.

The major weakness of anamorphic curves is the assumption of a common shape for all site classes. For some species, the height curve shape varies with site quality. Higher quality lands generally exhibit more pronounced sigmoid shapes and lower quality lands produce flatter height growth patterns. Polymorphic families of site index curves produce differing shapes for different site index classes (Avery and Burkhart, 1994). Though, polymorphic curves generally reflect height growth trends across a wide range of site qualities more accurately than anamorphic curves, the best accurate and precise estimation of equation depends on data set used.

The aims of this study, therefore, were 1) to construct site index curves for Douglas-fir grown Southland of New Zealand using the difference equation method, and 2) to confirm that whether developing a site index equation using the polymorphic form is more logical than using the anamorphic form or not.

\section{MATERIAL AND METHODS}

Data for this study came from a database of Douglas-fir (Psedostsuga menziesii Mirb. Franco) permanent sample plots grown in the Southland region of South Island of New Zealand, and maintained by New Zealand Forest Research Institute. All of 101 permanent sample plots, 218 sets of measurements, were used for analysis and measurement intervals were varied from 3 to 5 years. Plot sizes ranged from 0.01 to 0.2 hectare with a mean of 0.05 hectare. Mean age of trees was 32 years, while minimum and maximum ages were 7 and 76 years, respectively. A summary of relevant plot statistics is given in Table 1.

Table 1. A summary of permanent sample plots data

\begin{tabular}{lccc}
\hline Variables & Mean & Minimurn & Maximum \\
\hline Age (years) & 32.0 & 7.0 & 76.0 \\
Height (m) & 23.1 & 4.3 & 45.4 \\
Basal area (m²/ha) & 52.4 & 1.1 & 57.4 \\
Stocking (n/ha) & 1032 & 130 & 3168 \\
\hline
\end{tabular}


The method used for developing site index equation was the algebraic difference equation (Borders et al., 1984) which has been used widely for growth and yield modeling studies. The algebraic difference equation method for deriving site index equation requires permanent sample plots or stem analysis data. The procedure of formulating a difference equation is flexible and can be used with height and age equations to produce anamorphic and polymorphic family curves (Clutter et al., 1983). For example, height $\mathrm{H}_{2}$ at age $T_{2}$ is expressed as a function of $T_{2}$, height $H_{1}$ at age $T_{1}$ and $T_{1}$. A procedure of developing the difference equation is shown below using the Schumacher log reciprocal function.

A modified Schumacher height equation is given as:

$$
\begin{gathered}
\ln (\mathrm{H})=\alpha+\beta / \mathrm{T}^{\gamma} \\
\text { where, } \mathrm{H}=\text { height in meters } \\
\mathrm{T}=\text { age in years } \\
\alpha, \beta \text { and } \gamma=\text { coefficients to be estimated. }
\end{gathered}
$$

The heights are given by equations (2) and (3) at time $\mathrm{T}_{1}$ and $\mathrm{T}_{2}$ :

$$
\begin{aligned}
& \ln \left(\mathrm{H}_{1}\right)=\alpha+\beta / \mathrm{T}_{1}{ }^{\gamma} \\
& \ln \left(\mathrm{H}_{2}\right)=\alpha+\beta / \mathrm{T}_{2}{ }^{\gamma}
\end{aligned}
$$

Making $\beta$ the subject in equations (2) and (3), and equating the two resultant equations leads to equation (4):

$$
\mathrm{T}_{2}^{\gamma}\left(\ln \left(\mathrm{H}_{2}\right)-\alpha\right)=\mathrm{T}_{1}^{\gamma}\left(\ln \left(\mathrm{H}_{1}\right)-\alpha\right)
$$

Solving this equation for $\ln \left(\mathrm{H}_{2}\right)$, gives equation (5):

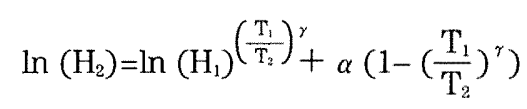

taking the exponent of equation (5) gives equation (6):

$$
\mathrm{H}_{2}=\mathrm{H}_{1}\left(\frac{\mathrm{T}_{1}}{\mathrm{~T}_{3}}\right)^{\gamma} \exp \left(\alpha\left(1-\left(\frac{\mathrm{T}_{1}}{\mathrm{~T}_{2}}\right)^{\gamma}\right)\right)
$$

When $\mathrm{T}_{2}$ in equation (6) is set equal to an index age (e.g. 40 years for Douglas-fir and 20 years for radiata pine in New Zealand), then $\mathrm{H}_{2}$ will be an explicit definition of site index.

The main standard statistical procedures used were non-linear least-squares regression based on PROC NLIN in Statistical Analysis System (SAS Inc, 1990). Analysis of residual statistics, through PROC UNIVARIATE was used to confirm the goodness of fit equations. Also, graphical charts and residuals plots were used to check the distributions of residuals with regard to normality of errors.

Various sigmoid functions were fitted to the data set using PROC NLIN (SAS Inc, 1990) and the derivative-free algorithmic methods for non-linear least-squares (Ralston and Jennrich, 1979). The general functional forms of equations used are presented in Table 2. 
Table 2. General form of projection equations applied to data

\begin{tabular}{lc}
\hline Equation name & Equation Forms \\
\hline Schumacher polymorphic & $\mathrm{H}_{2}=\exp \left(\mathrm{In}\left(\mathrm{H}_{\mathrm{i}}\right)\left(\mathrm{T}_{1} / \mathrm{T}_{2}\right)^{\beta}+\alpha\left(1-\left(\mathrm{T}_{1} / \mathrm{T}_{2}\right)^{\beta}\right)\right)$ \\
Chapman-Richards polymorphic & $\mathrm{H}_{2}=(\alpha / \gamma)^{[1 /(1-\beta)]}\left(1-\left(1-(\gamma / \alpha) \mathrm{H}_{1}^{(1-\beta)}\right) \exp (-\right.$ \\
& $\left.\left.\gamma(1-\beta)\left(\mathrm{T}_{2}-\mathrm{T}_{1}\right)\right)\right)^{[1 /(1-\beta)]}$ \\
Gompertz polymorphic & $\mathrm{H}_{2}=\exp \left(\mathrm{In}\left(\mathrm{H}_{1}\right) \exp \left(-\beta\left(\mathrm{T}_{2}-\mathrm{T}_{1}\right)+\gamma\left(\mathrm{T}_{2}{ }^{2}-\mathrm{T}_{1}{ }^{2}\right)+\alpha\right.\right.$ \\
& $\left.\quad\left(1-\exp \left(-\beta\left(\mathrm{T}_{2}-\mathrm{T}_{1}\right)+\gamma\left(\mathrm{T}_{2}{ }^{2}-\mathrm{T}_{1}{ }^{2}\right)\right)\right)\right)$ \\
Weibull polymorphic & $\mathrm{H}_{2}=\mathrm{H}_{1} \exp \left(-\beta\left(\mathrm{T}_{2}^{\gamma}-\mathrm{T}_{1}^{\gamma}\right)\right)+\alpha\left(1-\exp \left(-\beta\left(\mathrm{T}_{2}{ }^{\gamma}-\mathrm{T}_{1}{ }^{\gamma}\right)\right)\right)$ \\
Schumacher anamorphic & $\mathrm{H}_{2}=\mathrm{H}_{1} \exp \left(-\beta\left(1 / \mathrm{T}_{1}^{\gamma}-1 / \mathrm{T}_{2}{ }^{\gamma}\right)\right)$ \\
Hossfeld anamorphic & $\mathrm{H}_{2}=1 /\left(\left(1 / \mathrm{H}_{1}\right)+\beta\left(1 / \mathrm{T}_{2}{ }^{\gamma}-1 / \mathrm{T}_{1}{ }^{\gamma}\right)\right)$ \\
Chapman-Richards Anamorphic & $\mathrm{H}_{2}=\mathrm{H}_{1}\left(\left(1-\exp \left(-\beta \mathrm{T}_{2}\right)\right) /\left(1-\exp \left(-\beta \mathrm{T}_{1}\right)\right)\right)^{\gamma}$ \\
Gompertz anamorphic & $\mathrm{H}_{2}=\mathrm{H}_{1} \exp \left(-\beta\left(\exp \left(\gamma \mathrm{T}_{2}\right)-\exp \left(\gamma \mathrm{T}_{1}\right)\right)\right)$ \\
\hline
\end{tabular}

In order to determine the best model, candidate models were assessed by seeking a minimum mean square error (MSE), as well as observing the plot of residuals. Also, the following aspects were considered:

1) the residual patterns should have no bias;

2) the regression coefficient estimates of the $95 \%$ confidence interval should have the same sign;

3 ) the average mean of residual and skewness should be close to 0 , and kurtosis should lie between -2 and $+\infty$;

4) extreme values of residuals between positive and negative values should be similar.

The above tests, therefore, were used together, not just on their own, to avoid biased results and provide good fits to the equations.

\section{RESULTS AND DISCUSSION}

Firstly, several polymorphic models were applied such as the log-reciprocal equation (Schumacher, 1939; Woollons and wood, 1992), Chapman-Richards (Pienaar and Tunbull, 1973; Goulding, 1979), Gompertz (Whyte and Woollons, 1990) and Weibull (Yang et al., 1978; Goulding and Shirley, 1979). The fitted coefficients and mean square error are shown in Table 3.

Most of the polymorphic equations generally fitted well without bias in residuals pattern. Comparing residuals pattern and mean square error values the Gompertz polymorphic equation (7), was found to represent the best fit. Though the Chapman-Richard equation showed the smallest mean square error (MSE) value, which has been used first option for choosing the best fitting model because the equation with the least biased residual pattern has been often found to have the lowest MSE value, confidence interval of the coefficient of $\beta$ had the different sign. In order word, the coefficient was nor significant at the $\alpha=0.05$ level. 
Table 3. Coefficients for polymorphic equation fitted to data

\begin{tabular}{lrccc}
\hline \multirow{2}{*}{ Model Name } & \multicolumn{3}{c}{ Coefficients } & \multirow{2}{*}{ MSE } \\
\cline { 2 - 5 } & $\alpha$ & $\beta$ & $\gamma$ & 1.1905 \\
Schumacher polymorphic & 5.1484 & 0.4568 & - & 1.0513 \\
Chapman-Richards polymorphic & 0.6244 & 0.3120 & 0.0403 & 1.0865 \\
Gompertz polymorphic & 3.9130 & 0.0544 & 0.0002 & 1.1624 \\
Hossfeld polymorphic & 63.4332 & - & 1.4816 & \\
\hline
\end{tabular}

$$
\mathrm{H}_{2}=\exp \left(\ln \left(\mathrm{H}_{1}\right) \exp \left(-\beta\left(\mathrm{T}_{2}-\mathrm{T}_{1}\right)+\gamma\left(\mathrm{T}_{2}{ }^{2}-\mathrm{T}_{1}^{2}\right)+\alpha\left(1-\exp \left(-\beta\left(\mathrm{T}_{2}-\mathrm{T}_{1}\right)+\gamma\left(\mathrm{T}_{2}{ }^{2}-\mathrm{T}_{1}^{2}\right)\right)\right)\right)\right.
$$

This equation contained desirable functions commonly used in growth and yield models, such as compatibility, consistency; and path-invariance (Clutter et al., 1983). As $\mathrm{T}_{2}$ approaches infinitely, $\mathrm{H}_{2}$ approaches the upper asymptote $\alpha$, when $\mathrm{T}_{1}$ equals $\mathrm{T}_{2}$ then $H_{1}$ equals $H_{2}$ (consistency property), and the projection from $T_{1}$ to $T_{3}$ yields the same result as the projection from $T_{1}$ to $T_{2}$ followed by projection from $T_{2}$ to $T_{3}$ (path-invariance property).

A plot of residual values against predicted values is given in Figure 1; the data were evidently well balanced, with no apparent bias or systematic patterns and showed well goodness of fit. PROC UNIVARIATE in SAS showed that residual statistics were satisfactory as it contained -0.082 value for skewness and 0.231 value for kurtosis. The skeweness and kurtosis of a normal distribution is zero, but in practice values of these lesser or greater than zero result from least-square regression. A Shapiro-Wilk test for normality was totally accepted as 0.99 that is very closed to 1 of normal distribution. The equation gave a maximum residual of $3.1 \mathrm{~m}$, a minimum residual of $-3.0 \mathrm{~m}$, a mean residual of $0.062 \mathrm{~m}$ and $95 \%$ of residuals lay $\pm 1.7 \mathrm{~m}$.

The site index equation (8) can be derived from height equation (7) by setting $\mathrm{H}_{2}$ =site index (SI) when $\mathrm{T}_{2}=40$ years, which is the base age for Douglas-fir in New

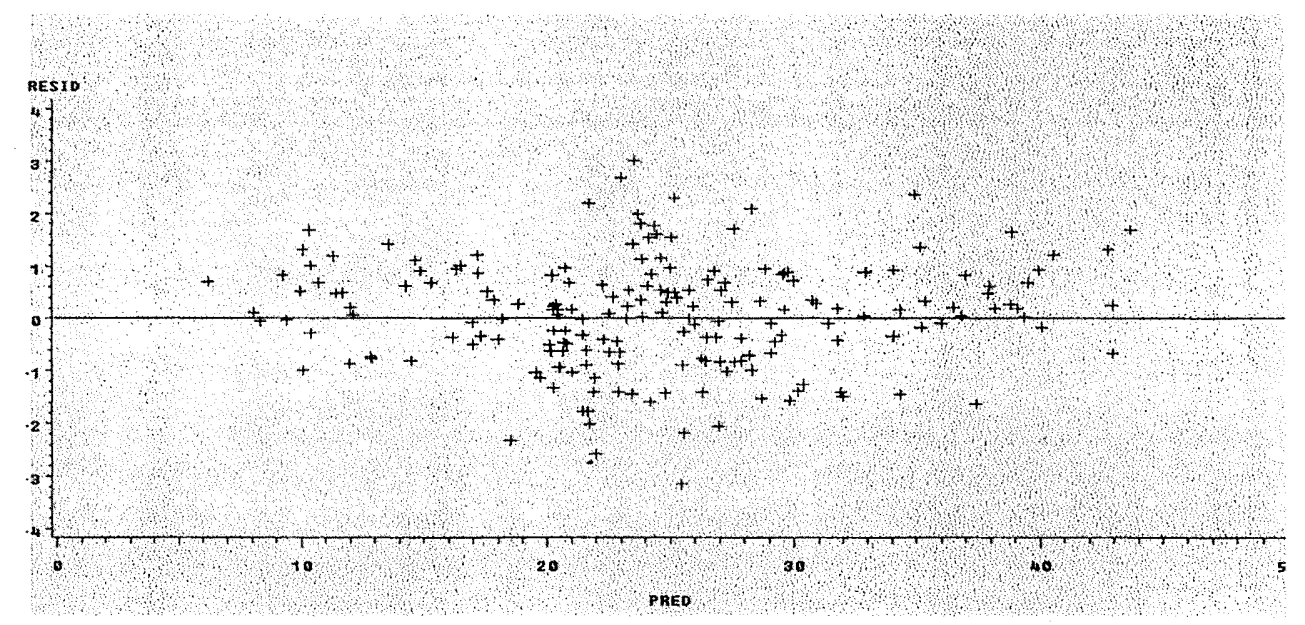

Fig. 1. Plot of residuals against predicted for Gompertz polymorphic height equation 
Zealand (Burkhart and Tennent, 1977; Lee, 1998).

$\mathrm{SI}=\exp \left(\ln \left(\mathrm{H}_{1}\right) \exp \left(-\beta\left(40-\mathrm{T}_{1}\right)+\gamma\left(40^{2-} \mathrm{T}_{1}^{2}\right)+\alpha\left(1-\exp \left(-\beta\left(40-\mathrm{T}_{1}\right)+\gamma\left(40^{2}-\mathrm{T}_{1}^{2}\right)\right)\right)\right)\right.$

Where, $\alpha=3.9130, \beta=0.0544$ and $\gamma=0.0002$

Site index curves can then be generated by rearranging equation (8) and making $\mathrm{H}_{1}$ the subject. Substituting SI with any required site index values (e.g. 20, 30, 40, and 50) results in polymorphic height growth curves. Figure 2 shows a set of site index curves resulted from equation (9).

$$
\mathrm{H}_{1}=\left[\frac{\mathrm{SI}}{\exp \left(\alpha\left(1-\exp \left(-\beta\left(40-\mathrm{T}_{1}\right)+\gamma\left(40^{2}-\mathrm{T}_{1}^{2}\right)\right)\right)\right)}\right]^{1 / \exp \left(-\beta\left(40-\mathrm{T}_{1}\right)+\gamma\left(40^{2}-\mathrm{T}_{1}^{2}\right)\right)}
$$

The previous developed site index equation for Douglas-fir grown in the South Island was an anamorphic form of equation which was developed by Temu (1992). Hence, several other frequently used anamorphic equations were also investigated for a comparative purpose. These were:

$$
\begin{aligned}
& \mathrm{H}_{2}=\mathrm{H}_{2} \exp \left(-\beta\left(1 / \mathrm{T}_{1}^{\gamma}-1 / \mathrm{T}_{2}^{\gamma}\right)\right) \\
& \mathrm{H}_{2}=\mathrm{H}_{1}\left(\left(1-\exp \left(-\beta \mathrm{T}_{1}\right)\right) /\left(1-\exp \left(-\beta \mathrm{T}_{2}\right)\right)\right)^{\gamma} \\
& \mathrm{H}_{2}=1 /\left(\left(1 / \mathrm{H}_{1}\right)+\beta\left(1 / \mathrm{T}_{2}^{\gamma}-1 / \mathrm{T}_{1}^{\gamma}\right)\right) \\
& \mathrm{H}_{2}=\mathrm{H}_{1} \exp \left(-\beta\left(\exp \left(\gamma^{-} \mathrm{T}_{2}\right)-\exp \left(\gamma \mathrm{T}_{1}\right)\right)\right)
\end{aligned}
$$

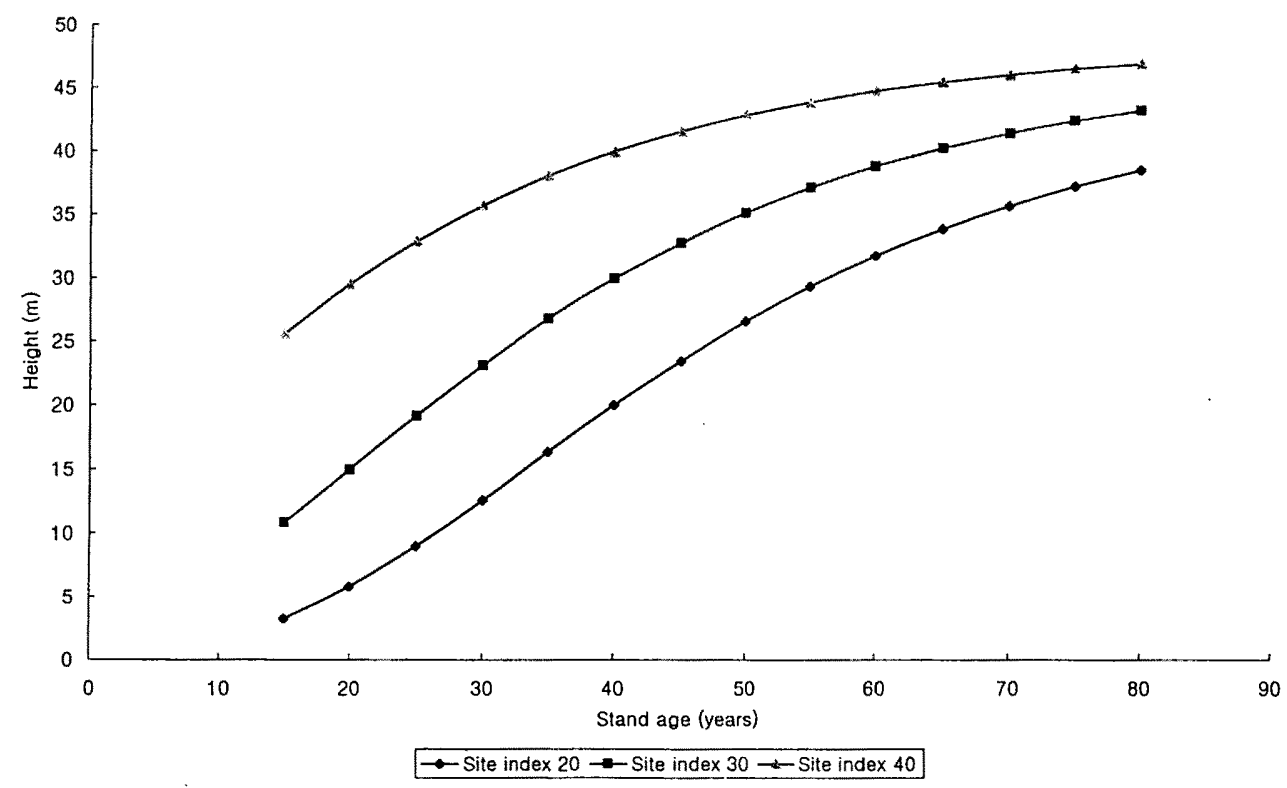

Fig. 2. Site index curves for Douglas-fir derived from a height equation 
Table 4. Coefficients for anamorphic equation fitted to data

\begin{tabular}{lcrrr}
\hline \multirow{2}{*}{ Model Name } & \multicolumn{3}{c}{ Coefficients } & \multirow{2}{*}{ MSE } \\
\cline { 2 - 4 } & $\alpha$ & \multicolumn{1}{c}{$\beta$} & \multicolumn{1}{c}{$\gamma$} & \\
\hline Schumacher anamorphic & - & 0.3145 & 8.5945 & 1.3245 \\
Chapman-Richards anamorphic & - & 0.0215 & -1.3307 & 1.3150 \\
Hossfeld anamorphic & - & -2.3289 & 1.2743 & 1.7595 \\
Gompertz anamorphic & - & -0.0489 & -1.8622 & 1.9097 \\
\hline
\end{tabular}

which were Schumacher, Chapman-Richard, Hossfeld and Gompertz functions respectively. Equation (13) quickly showed to be unsuitable with residuals pattern, while equations (10) and (12) proved inferior to the Chapman-Richard equation that had the lowest mean square error value. Hence, the anamorphic form of Chapman-Richards equation (11), was employed as the final site index equation because this combination produced the best fit among several anamorphic forms fitted. The coefficients of the anamorphic equations fitted are presented in Table 4 with respective mean square values.

A plot of residual against predicted values for equation (11), Figure 3, showed well fitting in general without apparent bias, but slightly less satisfactory than the residual plot in Figure 1. The mean of the average residuals and mean absolute values were $0.11 \mathrm{~m}$ and $0.87 \mathrm{~m}$ respectively, indicating that the equation slightly under-estimated tree height with an average deviation of $0.87 \mathrm{~m}$. Skewness and kurtosis values were 0.018 and 0.864 , respectively. Equation (11) was able to contain residuals all within $\pm 4.1 \mathrm{~m}$. This equation had a maximum residual of $3.5 \mathrm{~m}$, a minimum residual of $-4.1 \mathrm{~m}$.

When $\mathrm{T}_{2}$ in equation (14) is set equal to the desired index age, $\mathrm{H}_{2}$ is the site index by definition.

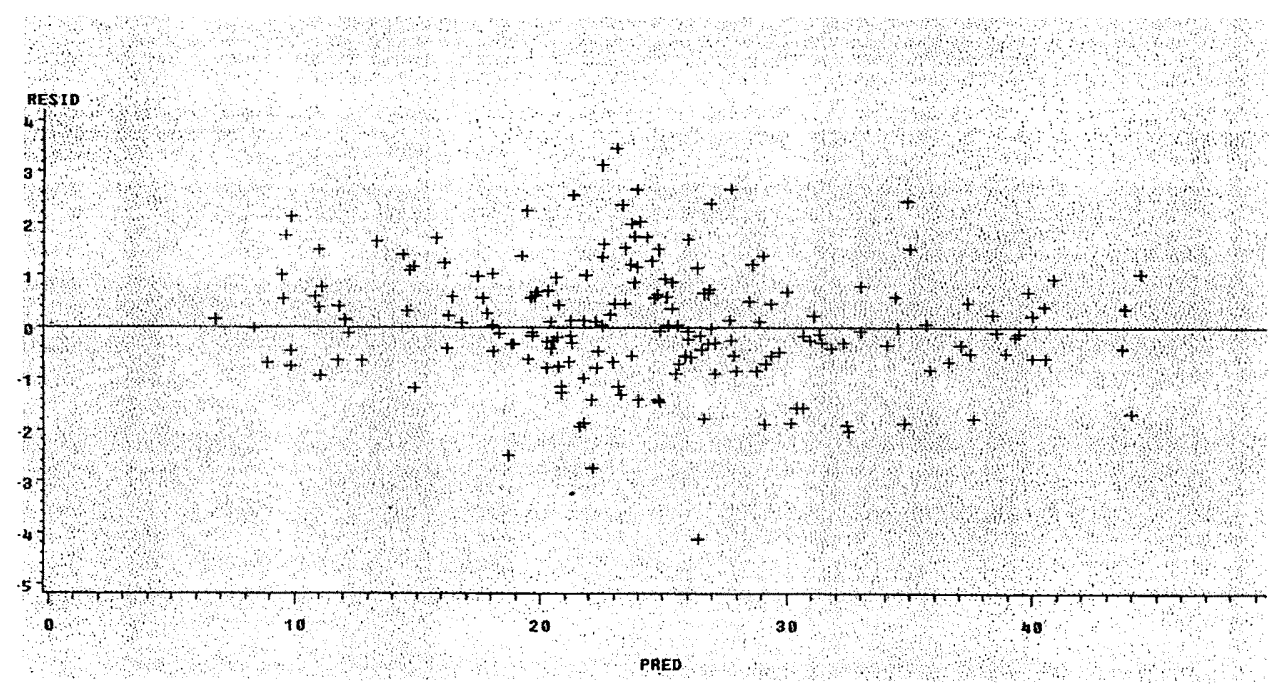

Fig. 3. Plot of residuals vs predicted for Chapman-Richard anamorphic height equation 


$$
\mathrm{S}=\mathrm{H}_{1}\left(\left(1-\exp \left(-\beta \mathrm{T}_{1}\right)\right) /\left(1-\exp \left(-\beta \mathrm{T}_{2}\right)\right)\right)^{\gamma}
$$

The result showed that both the polymorphic and the anamorphic equations provide estimates of height growth that were generally acceptable, with the average error within $0.87 \mathrm{~m}$ of the observed values. Statistics of residuals with the polymorphic equation were similar to those of the anamorphic equation, but slightly better.

Even though there were no significant differences in statistics between the anamorphic and polymorphic equations, the latter was preferred. The reason for this was that polymorphic curves generally reflected height growth trends over a wide range of site qualities more accurately than anamorphic curves.

\section{CONCLUSIONS}

It was clear that both the polymorphic and the anamorphic models (7) and (11), provided satisfactory models of the site index equation for Douglas-fir grown Southland of New Zealand, but the polymorphic form, equation (7), was somewhat superior. This was ensured by comparing the respective residual mean squares, where the polymorphic equation was lower in value, as well as better residual patterns and residual statistics.

It is unrealistic to expect a unique function to perform consistently better than others with forest growth and yield data. However, the initial selection of appropriate equations is most important for success of the goodness of fit models. In this research, the Gompertz polymorphic equation that reflects different shapes for the different site index classes was found to be the best model. The Gompertz function represents $T_{1}$ and $T_{2}$ as $\mathrm{T}_{2}-\mathrm{T}_{1}$, while the Hossfeld and Schumacher functions, which had the second third lower MSE values, encapsulate $T_{1}$ and $T_{2}$ as $T_{2} / T_{1}$. The applicability of the Gompertz function, therefore, is enhanced with data sets that contain longer or, medium measurement cycle data sets like this study.

\section{ACKNOWLEDGEMENTS}

The authors wish to thank to the New Zealand Forest Research Institute for providing data and appreciated Carter Harvey Ltd. for permission to use data.

\section{REFERENCES}

Assmann, E. 1970 The principles of forest yield study, Transrated by S. H. Gardiner. Pargamon Press, Oxford, $506 \mathrm{pp}$

Avery, T. E. and H. E. Burkhart 1994 Forest measurement. McGraw-Hill Book Co, New York, 408 pp

Borders, B. E., R. L. Bailey and K. D. Ware 1984 Slash pine index from a polymorphic model joining (splining) non-polynominal segments with an algebraic difference method. For. Sci., 30(2): 411-423

Burkhart. H. E. abd R. B. Tennent 1977 Site index equations for radiata pine in New Zealand. NZ. $J$. For. Sci., 7(3): 408-416

Clutter, J. L., J. C. Forsion, L. V. Pienaar, G. H. Brister and R. L. Bailey 1983 Timber management; a quantitative approach. John Wiley and Sons, New York, $333 \mathrm{pp}$

Goelz, J. C. and T. E. Burk 1992 Development of a well-behaved site index equation: jack pine in north central Ontario. Can. J. For. Res., 22: 776-784

Goulding, C. J. 1979 Validation of growth models for pinus radiata in New Zealand. N. Z. Jour. For, 24(1): 108-124 
Goulding, C. J. and J. W. Shirey 1979 A method to predict the yield of log assorments for long term planning. In Elliott, D. A. (Ed). Mensuration of management planning of exotic forest plantations. New Zealand Forestry Service and Forestry Research Institute Symposium No., 20: 301-314

Lanner, R. M. 1985 On the intensity of height growth to spacing. For. Eco. Mgmt., 13: 143-148

Lee, S. H. 1998 Modelling growth and yield of Douglas-fir using different interval lengths in the South Island of New Zeraland. Ph. D Thesis, School of Forestry, University of Canterbury, New Zealand, 239 pp

Pienaar, L. V. and K. J. Turnbull 1973 The Chapman-Richards generalization of Von Bertalanffy's model for basal area growth and yield in even -aged stands. For. Sci., 19: 2-22

Ralston, M. L. and R. I. Jennrich 1979 Dud, a derivative free algorithm for nonliner least squares. Technometrics, $\mathbf{2 0}(1): 7-13$

Rennols, K. 1995 Forest height modelling. For. Eco. Mgmt., 71: 217-225

SAS Institute Ine. 1990. SAS/STAT Procedures guide, Version 6, Cary, NC.

SAS Institute Inc. 1990. SAS/STAT User's guide, Version 6, Cary, NC.

Schumacher, F. X. 1939 A new growth curve and its application to timber-yield studies. J. For,, 37: $819-820$

Temu, M. J. 1992 Forecasting yield of Douglas fir in the South Island of New Zealand, Ph. D Thesis, School of Forestry, University of Canterbury, New Zealand, $246 \mathrm{pp}$

Whyte, A. G. D. and R. C. Woollons 1990 Modelling stand growth of radiata pine thinned to varying densities. Can. J. For. Res., 20: 1069-1076

Woollons, R. C. and G. R. Wood 1992 Utility and performance of five sigmoid yield-age functions fitted to stand growth data. Improving yield forecasting reliability through aggregated modelling. In: G. B. wood, and B. J. Turner (Eds). Proceedings IUFRO-Integrating Information Over space and Time; Australian National University Canberra, Jan; 13-17, 1992: 71-80

Yang, R. L., A. Kozak and H. J. G. Smith 1978 The potential of Weibull-type functions as flexible growth functions. Can. J. For. Res., 8: 424-431 